Rev Inv Vet Perú 2002; 13 (2): 61-65

\title{
SEROPREVALENCIA DEL VIRUS DE LA RINOTRAQUEITIS INFECCIOSA EN BOVINOS CRIOLLOS DE PARINACOCHAS, AYACUCHO
}

\author{
Erik Zacarías R. ${ }^{1}$, Alfredo Benito Z. ${ }^{2}$ y Hermelinda Rivera G. ${ }^{2,3}$
}

\section{Abstract}

The seroprevalence of Bovine Herpes Virus-1, the etiological agent of Infectious Bovine Rinotracheitis, was evaluated in criollo cattle from the districts of Coracora, Chumpi, Puyusca and Pullo of the Parinacochas Province, Ayacucho. A total of 469 serum samples from 25 herds were tested by virus neutralisation test to detect neutralizing antibodies. The $67.6 \pm 4.2 \%$ (317/469) of the samples had antibodies against BHV-1. The seroprevalence of the virus was similar in the animals of the 4 districts under evaluation. The antibody titers ranged from 2 to $>256$. All sampled herds had seroreactive animals. The study reported the presence of the BHV-1 in criollo cattle of the Parinacochas province, with a higher prevalence than the described in dairy herds in the country.

Key words: cattle, herpesviridae infections, bovine herpes virus-1 (BHV-1), infectious bovine rinotracheitis (IBR), neutralizing antibodies

\section{Resumen}

El objetivo del presente estudio fue conocer la prevalencia del Virus Herpes Bovino 1 (VHB-1), agente causal de la Rinotraqueitis Infecciosa Bovina, en bovinos criollos de crianza extensiva de los distritos de Coracora, Chumpi, Puyusca y Pullo de la provincia de Parinacochas, Ayacucho. Se analizaron 469 muestras de sueros bovinos procedentes de 25 hatos para la detección de anticuerpos neutralizantes mediante la prueba de neutralización viral. El $67.6 \pm 4.2 \%$ (317/469) de las muestras presentó anticuerpos neutralizantes con títulos entre 2 a $>256$. El $100 \%$ de los hatos muestreados tuvo animales seroreactores. La prevalencia del virus fue similar en los 4 distritos estudiados. Este estudio reporta la presencia del VHB-1 en bovinos criollos de la provincia de Parinacochas, con una prevalencia superior a lo descrito en bovinos de las principales cuencas lecheras del país.

Palabras clave: bovinos, infecciones herpesvirales, virus herpes bovino tipo 1 (VHB-1), rinotraqueitis infecciosa bovina (IBR), anticuerpos neutralizantes

\footnotetext{
${ }^{1}$ Práctica privada

${ }^{2}$ Laboratorio de Microbiología y Parasitología, FMV-UNMSM

${ }^{3}$ E-mail: hriverag@vet.unmsm.edu.pe
} 


\section{INTRODUCCIÓN}

En el Perú existen aproximadamente 4.5 millones de cabezas de ganado bovino, siendo únicamente el $14 \%$ de raza especializada y el $86 \%$ de tipo criollo. El ganado bovino se encuentra distribuido mayormente en la Sierra, en manos de pequeños y medianos criadores, bajo una crianza de tipo mixto y en forma extensiva, y pocos en forma semiintensiva (INEI, 1995). A pesar de que el ganado criollo constituye la mayor población bovina que se explota en el país, se tiene escasa información de los factores que limitan su desarrollo; entre ellos los problemas infecciosos, entre los que podrían estar involucrados las enfermedades infecciosas virales como la diarrea viral bovina, y la rinotraqueitis infecciosa bovina (RIB).

La RIB es una enfermedad causada por el Virus Herpes Bovino 1 (VHB-1), el cual se encuentra ampliamente distribuido en el mundo y es uno de los agentes más importantes que afectan el tracto respiratorio bovino. Está considerado como uno de los principales componentes del complejo respiratorio bovino presente en centros de engorde y en terneros de establos lecheros del país (Rivera et al., 1993; 1994). Estudios epidemiológicos y económicos realizados en bovinos de engorde en Estados Unidos y Canadá, indican que la enfermedad respiratoria bovina es causa de $75 \%$ de morbilidad y $65 \%$ de mortalidad, ocasionando grandes pérdidas económicas a los ganaderos (Zanabria et al., 2000).

El VHB-1 también es conocido por sus efectos abortogénicos, donde las vacas abortan debido a una secuela del problema respiratorio; aunque también por efecto directo del virus, sobre todo en el ganado carnicero de crianza extensiva, en donde puede producir brotes de abortos en el $25 \%$ de animales gestantes (Rickey, 1994).

Estudios realizados en el valle de Lima demuestran que la infección por VHB-1 está difundida en bovinos adultos (Rivera et al., 1993) y en terneros de hatos lecheros con problemas respiratorios (Rivera et al., 1994). Otros investigadores (Rosadio et al., 1993; Manchego et al., 1998) han documentado la presencia de anticuerpos contra el VHB-1 en bovinos lecheros, camélidos sudamericanos, ovejas y cabras de comunidades rurales de algunas áreas del Perú.

A pesar de que el VHB-1 ha sido detectado en la población bovina y en otras especies del país, no existen datos de su prevalencia en animales criollos. Es así que, el objetivo del presente estudio fue determinar la seroprevalencia del VHB-1 en bovinos criollos de crianza extensiva de la provincia de Parinacochas, a fin de contribuir al conocimiento de la epidemiología de la RIB en el país.

\section{Materiales y Métodos}

\section{Muestras}

Se utilizaron 469 muestras de suero de bovinos de crianza extensiva de la provincia de Parinacochas existentes en el banco de sueros del Laboratorio de Virología de la Facultad de Medicina Veterinaria (FMV) de la Universidad Nacional Mayor de San Marcos (UNMSM). Las muestras fueron obtenidas a fines del año 2000 para el estudio de seroprevalencia de la brucelosis bovina. Las muestras corresponden a vacas y vaquillonas de 25 hatos distribuidos en los distritos de Coracora, Chumpi, Puyusca y Pullo de la provincia de Parinacochas, Ayacucho.

\section{Detección de Anticuerpos Neutralizantes Contra el VHB-1}

La detección de los anticuerpos se realizó mediante la prueba de neutralización viral, según el protocolo disponible en el Laboratorio de Virología de la FMV de la UNMSM. 


\section{Rrsultados}

El $67.6 \pm 4.2 \%(317 / 469)$ de las muestras de suero tuvieron anticuerpos contra el VHB-1, sin que se encuentre diferencias entre distritos (Cuadro $1 ; \mathrm{p}>0.05$ ).
Todos los hatos evaluados tuvieron animales seroreactores al virus, con niveles de serorreactividad entre el 25.0 y $90.9 \%$. Los títulos de anticuerpos contra el virus variaron entre 2 a $>256$ (Fig. 1).

Cuadro 1. Seroprevalencia del VHB-1 en bovinos criollos de 4 distritos de la provincia de Parinacochas, Ayacucho. 2000

\begin{tabular}{lcccc}
\hline \multirow{2}{*}{ Distritos } & $\begin{array}{c}\mathrm{N}^{\circ} \text { Animales } \\
\text { muestreados }\end{array}$ & $\begin{array}{c}\mathrm{N}^{\circ} \text { de } \\
\text { hatos }\end{array}$ & \multicolumn{3}{c}{$\begin{array}{c}\text { Animales con anticuerpos contra } \\
\text { el VHB-1 }\end{array}$} \\
\cline { 4 - 5 } & & & $\mathrm{n}$ & $\%$ \\
\hline Coracora & 132 & 8 & 82 & $62.1 \pm 8.3$ \\
Chumpi & 95 & 4 & 72 & $75.8 \pm 8.6$ \\
Puyusca & 141 & 7 & 93 & $66.0 \pm 7.8$ \\
Pullo & 101 & 6 & 70 & $69.3 \pm 9.0$ \\
\hline Total & 469 & 25 & 317 & $67.6 \pm 4.2$ \\
\hline
\end{tabular}

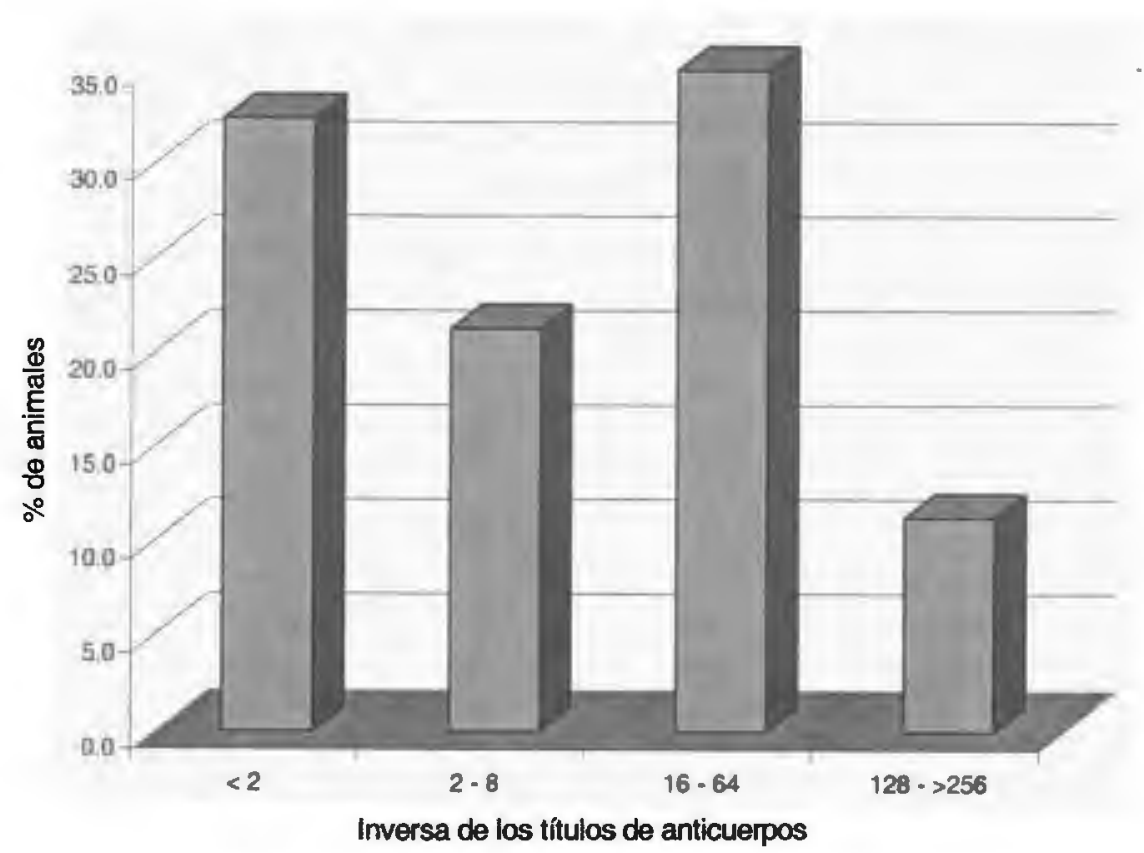

Figura 1. Distribución de los títulos de anticuerpos neutralizantes contra el VHB-1, en bovinos criollos de la provincia de Parinacochas, Ayacucho. 2000 


\section{Discusión}

Según las normas vigentes para el tránsito interno de animales, dispuestas por el SENASA, Ministerio de Agricultura, los bovinos con certificado sanitario de negatividad a brucelosis, tuberculosis y fiebre aftosa pueden ser movilizados de un lugar a otro del país. Este reglamento no contempla enfermedades infecciosas como leucosis, rinotraqueitis infecciosa bovina, etc., que fácilmente podrían ser introducidas a zonas libres, donde podrían difundirse rápidamente al encontrar una población de animales susceptibles.

El 67.6\% (317/469) de los bovinos criollos de la provincia de Parinacochas, Ayacucho, presentaron anticuerpos neutralizantes contra el VHB-1, agente causal de la RIB, significando que estos animales fueron expuestos al virus en algún momento de sus vidas. Los ganaderos manifiestan que no vacunan contra la RIB, de modo que los anticuerpos detectados fueron inducidos por el virus de campo (Cuadro 1). Los porcentajes de animales serorreactores al VHB-1 fueron similares en los 4 distritos de la provincia en estudio en donde la totalidad de los hatos tuvieron animales seroreactores, lo que indica que la RIB tiene amplia distribución en la región del estudio.

Esta alta prevalencia del VHB-1 en animales criollos con un tipo de crianza mayormente extensiva contrasta con el $22.6 \%$ reportado en bovinos lecheros de crianza intensiva y $36.5 \%$ en bovinos de centros de engorde de Lima (Rosadio et al., 1993). En forma similar, se ha reportado recientemente en un estudio de prevalencia del VHB-1 realizado en bovinos lecheros de crianza intensiva y sin historia de vacunación del valle de Lima que el $35 \%$ de los animales muestreados tuvieron anticuerpos contra el virus (Sánchez G., en prensa). Estas diferencias podrían deberse a que el virus es más fácilmente reactivado en animales de crianza extensiva de esta zona debido a ciertos factores estresantes como la falta de pastos, parasitosis etc., o que el virus haya sido recientemente introducido al área a través de animales infectados.

Los títulos encontrados indican que el virus estuvo activo en los animales del hato durante el muestreo, posiblemente como infecciones primarias o recurrentes tras reactivaciones del estado de latencia (Smith, 1997), induciendo una fuerte respuesta humoral. Los anticuerpos neutralizantes, principalmente de tipo IgM seguido por las IgG pueden ser detectados 10 días postinfección (Engels y Ackermann, 1996). El 11.3\% de animales con altos títulos de anticuerpos sugiere desafíos recientes posiblemente con consecuencias clínicas de RIB, pues títulos altos de anticuerpos han sido detectados durante brotes de complejo respiratorio con el VHB-1 como agente primario (Rivera et al., 1994) y en un brote de abortos en yeguas debido al virus herpes equino tipo 1 (Rivera et al., 1997); aunque también las infecciones producto de reactivaciones pueden ser de tipo subclínico pero con seroconversión (Van Oirschot, 1995).

Desafortunadamente no se dispone de información del estado sanitario de los animales, pero la presencia del virus en los animales de todos los hatos muestreados podría estar afectando el tracto respiratorio y estar siendo confundido con neumonías parasitarias, sobre todo en animales jóvenes. La infección por el VHB-1 en el animal adulto suele ser subclínica sirviendo de fuente del virus para los animales jóvenes (Rivera et al., 1994). Los efectos de mayor relevancia de los virus herpes es a nivel del tracto respiratorio ocasionando rinotraqueitis propiamente dicha o como complejo respiratorio conjuntamente con otros virus, como la Parainfluenza 3, y la diarrea viral bovina; bacterias como la Pasteurella haemolytica; y larvas de parásitos. En el tracto genital puede ocasionar la vulvovaginitis y balanopostitis causando abortos aunque este último es más una secuela del problema respiratorio. Por otro lado, hay reportes de cepas con cierto potencial abortogénico que pueden ocasionar brotes de abortos (Miller et al., 1991). 
La provincia de Parinacochas con aproximadamente 32,790 cabezas de bovinos (INEI, 1995) representa un gran potencial para el desarrollo de la ganadería lechera. Distritos como Coracora, Chumpi, Puyusca y Pullo, que poseen la mayor población de bovinos indican estar libres de brucelosis (datos por publicarse) y tuberculosis (Sánchez, 2002). Estos resultados podrían servir de base para determinar el rol del virus del RIB en la presentación de neumonías en los animales y contribuir a mejorar el estado sanitario de esta importante población de ganado criollo del país.

\section{Agradecimientos}

Los autores agradecen al Sr. Lesmes Valdivia P. por su colaboración en la conformación del Banco de Sueros de bovinos procedentes de la Provincia de Parinacochas, usados en el presente estudio.

\section{Limbratura CtTada}

1. Engels, M.; M. Ackermann. 1996. Pathogenesis of ruminant herpesvirus infections. Vet. Microbiol. 53: 3-15.

2. INEI. Instituto Nacional de Estadistica e Informática. 1995. III Censo Nacional Agropecuario: Resultados Definitivos, Departamento de Ayacucho. Tomo II. p 152-203. Lima. Perú.

3. Manchego, A.; H. Rivera; R. Rosadio. 1998. Seroprevalencia de agentes virales en rebaños mixto de una comunidad andina Peruana. Rev. Inv. Pec. IVITA (Perú) 9:1-10.

4. Miller, J.; C. Whetstone; M. Van der Maaten. 1991. Abortifacient potential of bovine herpesvirus tipo 1 isolates that represent three subtypes determined by restriction endonuclease analysis of viral DNA. American. J. Vet. Res. 52: 458461.

5. Richey, E. 1994. IBR in beef cattle (Infectious bovine rhinotracheitis/red nose). VM-55. University of Florida, Institute of Food And Agricultural Sciences.

6. Rivera, H.; A. Manchego; N. Sandoval; A. Vargas; A. Araujo; A. Gonzáles; $R$. Rosadio. 1993. Aborto infeccioso en bovinos de leche del valle de Lima. Rev. Inv. Pec. IVITA (Perú) 6: 31-37.

7. Rivera, H.; A. Manchego; N. Sandoval; C. Morales; E. Flores. 1994. Complejo respiratorio bovino en terneros del valle de Lima. Rev. Inv. Pec. IVITA (Perú) 7: 35-38.

8. Rivera, H.; R. Alvitres; A. Manchego; N. Sandoval; R. Rosadio. 1997. Aborto por virus herpes equino. Rev. Inv. Pec. IVITA (Perú) 8: 49-55.

9. Rosadio, R.; H. Rivera; A. Manchego. 1993. Prevalence of neutralising antibodies to bovine herpesvirus-1 in Peruvian livestock. Vet. Rec. 132: 611612.

10. Sánchez, D. 2002. Prevalencia de la tuberculosis bovina en la provincia de Parinacochas, Ayacucho. Tesis Bachillerato. Fac. Med. Vet., Univ. Nac. Mayor San Marcos, Lima, 42 p.

11. Smith, K. 1997. Herpesviral abortion in domestic animals. Vet. J. 153: 253-268.

12. Van Oirschot, J. 1995. Bovine herpesvirus 1 in semen of bulls and the risk of transmission: a brief review. Veterinary Quarterly 17: 29-33.

13. Zanabria, V.; H. Rivera; R. Rosadio. 2000. Etiología del síndrome neumónico agudo en vacunos de engorde en Lima. Rev. Inv. Vet. Perú 11: 67-85. 